\title{
Performance of the Vaginal Touch in the Diagnosis of Vertex Presentation in Posterior Variety
}

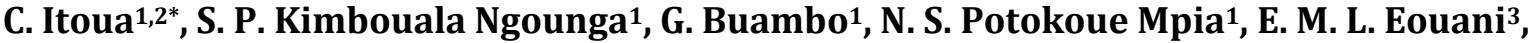 \\ L. H. Iloki ${ }^{1,2}$ \\ ${ }^{1}$ Gynecology and Obstetric Department, University Hospital of Brazzaville, Brazzaville, Congo \\ ${ }^{2}$ Faculty of Health and Sciences, Marien Ngouabi University of Brazzaville, Brazzaville, Congo \\ ${ }^{3}$ Gynecology and Obstetric Department, Hospital of Loandjili, Pointe Noire, Congo \\ Email: *clautairei@yahoo.com
}

How to cite this paper: Itoua, C., Kimbouala Ngounga, S.P., Buambo, G., Potokoue Mpia, N.S., Eouani, E.M.L. and Iloki, L.H. (2018) Performance of the Vaginal Touch in the Diagnosis of Vertex Presentation in Posterior Variety. Open Journal of Obstetrics and Gynecology, 8, 1305-1309. https://doi.org/10.4236/ojog.2018.813132

Received: October 1, 2018

Accepted: November 2, 2018

Published: November 5, 2018

Copyright $\odot 2018$ by authors and Scientific Research Publishing Inc. This work is licensed under the Creative Commons Attribution International License (CC BY 4.0).

http://creativecommons.org/licenses/by/4.0/

\begin{abstract}
Objective: To evaluate the performance of the vaginal touch in the diagnosis of vertex presentation in posterior variety. Materials Populations and Methods: Transversal analytical study conducted during 4 months (November 2017 - February 2018) at the University Hospital of Brazzaville. This study included parturients with a living foetus in term and in vertex presentation. The membranes were broken with less than $6 \mathrm{~cm}$ of vaginal dilatation. In each case the ultrasound was associated to verify the accuracy of the results of vaginal examination. The statistical tests used were: sensitivity, specificity, positive and negative predictive values, and Youden's index. Results: One hundred and twenty-two vertex presentations were recorded, of which 31 (25.4\%) had a posterior variety diagnosed successively with vaginal examination and ultrasound, while 23 (42.6\%) were only on ultrasound. Parturients with foetuses in the posterior and anterior variety were similar in median age (30 [25.5 - 33.5] vs $27.5[24-34], \mathrm{p}>0.05)$ and parity (2 [1.5 - 3.5] vs 2 [1 $3], \mathrm{p}>0.05)$. Vaginal touch had: sensitivity of $57.4 \%$ [44.4 - 70.4], specificity of $94.1 \%$ [86.7 - 99.3], and Youden's index of 0.52 . The positive and negative predictive values were respectively $88.5 \%$ and $73.5 \%$. The vaginal examination was influenced by: examiner ( $\mathrm{OR}=2.7$ [1.21 - 6.07]; $\mathrm{p}<0.05)$, sero-sanguine hump (OR $=7.5$ [2.38 - 23.77]; $\mathrm{p}<0.05)$, and $\mathrm{BMI}>25 \mathrm{~kg} / \mathrm{m}^{2}(\mathrm{OR}=3.4[1.07$ - 11.07], $\mathrm{p}<0.05)$. Conclusion: The vaginal touch is not very effective in the diagnosis of the vertex presentation in posterior variety.
\end{abstract}

\section{Keywords}

Vaginal Touch, Vertex Presentation, Posterior Variety, Brazzaville 


\section{Introduction}

The presentation of the vertex is that of the head well bent so that the part of the head which goes down first, and at the same time which serves as a reference for the designation of the variety of position is the occiput. According to the occiput posterior to the sacroiliac sinus, two posterior varieties are defined: the posterior right occipito-iliac (33\%) and the posterior left occipito-iliac (6\%) [1]. Ultrasound can visualize cephalic structures and has a diagnostic accuracy of 95\% [2] [3] [4]. The diagnosis of the posterior variety is also clinical by the vaginal touch, based on the perception of the occiput and the sagittal suture.

The aim of this study is to evaluate the performance of vaginal examination in the diagnosis of posterior vertex presentation.

\section{Materials, Populations and Methods}

It was a cross-sectional analytical study, conducted from 1 November 2017 to 28 February 2018 in the Gynaecology and Obstetric department of the University Hospital of Brazzaville. Parturients with broken membranes, less than $6 \mathrm{~cm}$ of cervical dilatation, living foetus, and at the vertex presentation were considered. For each case diagnosed by vaginal examination, a transabdominal ultrasound was performed using a Mindray DP 1100 hand-held $3.5 \mathrm{MHz}$ transducer. The diagnosis of the positional variability of the presentation was made by mapping the medial structures of the fetal brain (median echo, thalami and false of the brain, septum of the cavum pallidum, cerebellum) and the elements of the fetal face (ocular orbits and nose). The following parameters were analyzed:

- demographic and reproductive: age, parity, body mass index (BMI) calculated in the first trimester;

- clinical: the qualifier of the examiner, the variety of position, the existence or not of the sero-sanguine hump;

- ultrasound: the variety of position;

- vaginal examination: sensitivity, specificity, positive and negative predictive values, Youden's index

(https://www.researchgate.net/post/What_is_Youdens_index_J_and_its_usag e: 10/09/2018).

The data was analysed from the info7 epi software. The Chi-2 and Man Whitney tests assessed the association between two variables and the odds ratio with $95 \%$ confidence interval for each measure. The $\mathrm{p}$ value of the probability was considered significant for a value $<0.05$. This study has been approved by the national ethics committee in accordance with the Helsinki recommendations.

\section{Results}

One hundred and twenty-two vertex presentations were recorded, of which 31 (25.4\%) had a posterior variety diagnosed successively with vaginal touch and ultrasound, while 23 (42.6\%) were only on ultrasound. Parturient foetuses with 
vertex posterior and posterior variety had similar age and parity (Table 1 ). The diagnosis of the posterior variety was influenced by the examiner $(\mathrm{OR}=9.3$ [2.26 - 37.72]; $\mathrm{p}<0.05)$, the sero-sanguine hump during vaginal examination $(\mathrm{OR}=4.9[1.15-21.61], \mathrm{p}<0.05)$, and a BMI $>25 \mathrm{~kg} / \mathrm{m}^{2}(\mathrm{OR}=3.4[1.07-$ 11.07], $\mathrm{p}<0.05)$. The results of vaginal touch in the diagnosis of the posterior variety in the vertex presentation are in Table 2. Table 3 represents the indices of performance of vaginal touch in the diagnosis of vertex presentation in posterior variety.

Table 1. Demographic and clinical characteristics of parturients.

\begin{tabular}{|c|c|c|c|c|c|}
\hline \multicolumn{6}{|c|}{ Vertex presentation $(\mathrm{N}=122)$} \\
\hline & Posterior varieties & $\begin{array}{l}\text { Non-posterior } \\
\text { varieties }\end{array}$ & & & \\
\hline & & & OR & IC (95\%) & $\mathrm{p}$ \\
\hline Median age [q1 - q3] & $30[25.5-33.5]$ & $27.5[24-34]$ & & & $>0.05$ \\
\hline Median parity [q1 - q3] & $2[1.5-3.5]$ & $2[1-3]$ & & & $>0.05$ \\
\hline BMI n (\%) & & & 3.4 & $1.07-11.07$ & $<0.05$ \\
\hline - Normal & $24(44.4)$ & $47(69.1)$ & & & \\
\hline - Overweight & $20(37.1)$ & $16(23.5)$ & & & \\
\hline - Obesity & $10(18.5)$ & $5(7.4)$ & & & \\
\hline Examiner n (\%) & & & 2.7 & $1.21-6.07$ & $<0.05$ \\
\hline - Specialist & $21(52.5)$ & $31(35.6)$ & & & \\
\hline - Student & $14(47.5)$ & $56(64.4)$ & & & \\
\hline Sero-sanguine hump n (\%) & $11(31.4)$ & $5(5.7)$ & 7.5 & $2.38-23.77$ & $<0.05$ \\
\hline
\end{tabular}

Table 2. Results of vaginal touch in the diagnosis of the posterior variety in the vertex presentation.

\begin{tabular}{ccccccc}
\hline \multicolumn{7}{c}{ Trans abdominal ultrasound (N = 122) } \\
\hline & \multicolumn{7}{c}{ Posterior variety } & Non-posterior variety & \\
\hline & $\mathrm{n}$ & $\%$ & $\mathrm{n}$ & $\%$ & Total \\
\hline $\begin{array}{c}\text { Vaginal } \\
\text { touch }\end{array}$ & Test + & $31^{(1)}$ & 57.4 & $4^{(3)}$ & 5.9 & 35 \\
$(\mathrm{~N}=122)$ & Test - & $23^{(2)}$ & 42.6 & $64^{(4)}$ & 94.1 & 87 \\
Total & 54 & 100.0 & 68 & 100.0 & 122 \\
\hline
\end{tabular}

${ }^{(1)}$ True Positive; ${ }^{(2)}$ False negative; ${ }^{(3)}$ False positive; ${ }^{(4)}$ True negative.

Table 3. Indices of performance of vaginal touch in the diagnosis of vertex presentation in posterior variety.

\begin{tabular}{cc}
\hline \multicolumn{2}{c}{ Performance indices of vaginal touch } \\
\hline Sensitivity & $57.4 \%$; IC $(95 \%)[44.4-70.4]$ \\
Specificity & $94.1 \%$; IC $(95 \%)[86.7-99.3]$ \\
Positive predictive value & $88.5 \%$ \\
Negative predictive value & $73.5 \%$ \\
Youden's index & 0.52 \\
\hline
\end{tabular}




\section{Discussion}

Some patients had been examined by students in their final year of specialization in gynecology obstetric. This could be considered a weakness of this survey due to possible information bias. Nevertheless, the large size of the sample, the rigor of the inclusion rules and the statistical tests used are scientific assets of this work. The vaginal touch is an essential time of diagnosis of the foetus presentation varieties in our work environment. In our context, statistics on vertex position varieties remain approximate because of the systematic non-use of ultrasound. Vaginal touch was considered poor in the diagnosis of the posterior variety in our study with a Youden's index of 0.52 .

In fact the frequency of the posterior variety increased from $25.4 \%$ to $44.3 \%$ thanks to ultrasound. It is a reference examination to study the reliability of vaginal touch in the variety of position [2] [3] [4] [5]. In the literature, the performance of vaginal examination is variously estimated with the ultrasound agreement rates ranging from $20.5 \%$ to $71.6 \%$, dependent on the labour phase, the foetus, the mother and the examiner [5] [6] [7] [8] [9]. Thus, in the first phase of the labour of delivery, our frequency of cephalic presentations of the summit in posterior varieties is close to those reported by Hidar [5] in Tunisia of $40.2 \%$ and Blasi [6] in Germany by $51 \%$.

However, the vaginal examination data vary according to the dilatation, as evidenced by the lower frequency of 33\% reported by Akmal [7] in England at the second phase of labour, in relation to the spontaneous rotation of the varieties. In relation to the usual spontaneous rotation of the posterior varieties prior to this stage to disengage in occipito-pubic. The examiner's grade influenced the diagnosis of the post variety. The same observation was made by Sherer [8], who found a clinico-echographic concordance of $33 \%$ for residents and $58 \%$ for specialists. In the same vein Kamal [7] reported greater accuracy among experienced examiners with an odd ratio of 2.4 IC [1.08 - 5.3]. Similarly, a BMI $>25$ $\mathrm{kg} / \mathrm{m}^{2}$ multiplies by a factor of 3 the risk of not diagnosing a variety after vaginal touch. The inconvenience of vaginal examination in overweight and obese parturients may explain the difficulties in accurately obtaining variety of position. Like other authors [7] [9], sero-sanguine hump has disturbed the result of vaginal examination in the diagnosis of the variety of position. Frequent in the context of posterior variety, the sero-sanguine hump makes posterior fontanel difficult to spot.

\section{Conclusion}

The vaginal touch is inefficient in the diagnosis of vertex presentation in posterior variety. The practice of ultrasound would need to be popularized in the birth room.

\section{Conflicts of Interest}

The authors declare no conflicts of interest regarding the publication of this paper. 


\section{References}

[1] Merger, R., Lévy, J. and Melchior, J. (2001) Précis d'obstétrique. 6th Edition, Masson, Paris, 163-164.

[2] Chou, M.R., Kreiser, D., Taslimi, M.M., Druzin, M.L. and El-Sayed, Y.Y. (2004) Vaginal versus Ultrasound Examination of Fetal Occiput Position during the Second Stage of Labor. American Journal of Obstetrics \& Gynecology, 191, 521-524. https://doi.org/10.1016/j.ajog.2004.01.029

[3] Depuis, O., Ruimark, S., Corinne, D., Simone, T., André, D. and René-Charles, R. (2005) Fetal Head Position during the Second Stage of Labor: Comparison of Digital Vaginal Examination and Transabdominal Ultrasonographic Examination. European Journal of Obstetrics, Gynecology, and Reproductive Biology, 123, 193-197. https://doi.org/10.1016/j.ejogrb.2005.04.009

[4] Kresier, D., Schiff, E., Lipitz, S., Kayam, Z., Avraham, A. and Achiron, R. (2010) Determination of Foetal Occiput Position by Utrasound during the Second Stage of Labor. Journal of Maternal-Fetal \& Neonatal Medicine, 10, 283-286. https://doi.org/10.1080/jmf.10.4.283.286

[5] Hidar, S., Choukou, A., Jerbi, M., Chaïeb, A., Bibi, M. and Khaïri, H. (2006) Diagnostic clinico-echographique etdevenir des varietes postérieures dans la présentation du sommet: étude prospective longitudinale de 350 parturientes. Gynécologie Obstétrique \& Fertilité, 34, 484-488. https://doi.org/10.1016/j.gyobfe.2005.11.011

[6] Blasi, I., D’amico, R., Fenu, V., Volpe, A., Fuchs, I., Henrich, W., et al. (2010) Sonographic Assessment of Fetal Spine and Head Position during the First and Second Stage of Labor for Diagnosis of Persistent Occiput Position: Pilot Study. Ultrasound in Obstetrics \& Gynecology, 35, 210-215. https://doi.org/10.1002/uog.7504

[7] Akmal, S., Kametas, N., Tsoi, E., Howard, R. and Nicolaides, K.H. (2004) Ultrasonographic Occiput Position in Early Labour in the Prediction of Caesarean Section. BJOG, 111, 532-536. https://doi.org/10.1111/j.1471-0528.2004.00134.x

[8] Sherer, D.M., Miodovnik, M., Bradley, K.S. and Langer, O. (2002) Intrapartum Fetal Head Position I: Comparison between Transvaginal Digital Examination and Transabdominal Ultrasound Assessment during the Second Stage of Labor. Ultrasound in Obstetrics \& Gynecology, 19, 258-263.

https://doi.org/10.1046/j.1469-0705.2002.00656.x

[9] Riethmuller, D., Teffaud, O. and Eyraud, J.L. (1999) Pronostic maternel et fotal du dégagement en occipito-sacré. Journal de Gynécologie Obstétrique et Biologie de la Reproduction, 28, 41-47. 